\title{
The Transporter Associated With Antigen Processing (TAP): Structural Integrity, Expression, Function, and Its Clinical Relevance
}

\author{
Ulrike Ritz and Barbara Seliger \\ Johannes Gutenberg-University III, Department of Internal Medicine, Mainz, Germany \\ Accepted December 28, 2000.
}

\begin{abstract}
Background: The transporter associated with antigen processing (TAP), a member of the family of ABC transporters, plays a crucial role in the processing and presentation of the major histocompatibility complex (MHC) class I restricted antigens. TAP transports peptides from the cytosol into the endoplasmic reticulum, thereby selecting peptides matching in length and sequence to respective MHC class I molecules. Upon loading on MHC class I molecules, the trimeric MHC class $\mathrm{I} / \beta_{2}$-microglobulin/ peptide complex is then transported to the cell surface and presented to $\mathrm{CD}^{+}$cytotoxic $\mathrm{T}$ cells. Abnormalities in
\end{abstract}

MHC class I surface expression have been found in a number of different malignancies, including tumors of distinct histology, viral infections, and autoimmune diseases, and therefore represent an important mechanism of malignant or virus-infected cells to escape proper immune response. In many cases, this downregulation has been attributed to impaired TAP expression, which could be due to structural alterations or dysregulation. This review summarizes the physiology and pathophysiology of TAP, thereby focusing on its function in immune responses and its role in human diseases.

\section{Introduction}

The MHC class I molecules present mainly cytosolic peptides to MHC class I restricted $\mathrm{CD}^{+}$cytotoxic T lymphocytes (CTL). Most of these peptides are generated by degradation of intracellular proteins, which is directed by both constitutive and interferon (IFN) $-\gamma$ inducible proteasomal subunits. The yielded peptides are then transported by TAP from the cytosol into the lumen of the endoplasmic reticulum (ER), where they are loaded onto a dimer consisting of MHC class I heavy chain (HC) and $\beta_{2^{-}}$ microglobulin $\left(\beta_{2}-\mathrm{m}\right)$. Both steps - the assembly of these molecules and the formation of the "large TAP complex"-are stabilized by various ER-resident chaperones, such as calnexin, binding protein (BiP), calreticulin, the oxidoreductase ERp57, and the transmembrane protein tapasin (1-3). Tapasin further retains empty MHC class I molecules in the ER and facilitates their peptide loading $(4,5)$. The stable MHC class I $\mathrm{HC} / \beta_{2}-\mathrm{m} /$ peptide complex is then transported via the trans-golgi to the cell

Address correspondence and reprint requests to: Barbara Seliger, $\mathrm{PhD}$, Johannes Gutenberg University, Department of Internal Medicine, Langenbeckstrasse 1, 55101 Mainz, Germany. Phone: +49-6131-176760; Fax: +49-6131-176678; E-mail: B.Seliger@

3-med.klinik.uni-mainz.de surface for recognition by $\mathrm{CD}^{+} \mathrm{T}$ cells (recently reviewed in 6, 7; Fig. 1).

\section{The Superfamily of $A B C$ Transporters}

TAP belongs to the superfamily of ATP-binding cassette $(\mathrm{ABC})$ transporters. All $\mathrm{ABC}$ transporters possess two hydrophobic $\mathrm{N}$-terminal domains crossing the membrane six to eight times, thereby forming a putative translocation pore and two highly conserved C-terminal cytosolic adenosine triphosphate (ATP)-binding cassettes (Fig. 2). For their proper function, energy in the form of nucleoside triphosphates (NTP) is required. ABC transporters translocate a diverse set of substances/molecules, such as ions, sugars, polysaccharides, amino acids, and oligo- and polypeptides across cell membranes. Each transporter is specialized for the transport of a unique substrate or substrate class and plays an important role in different (patho)physiologic processes (8).

Until now, the best characterized ABC transporters in vertebrates are the cystic fibrosis transmembrane conductance regulator (CFTR; 9,10), a chloride channel that is deficient in cystic fibrosis; the sulfonylurea receptor (SUR) 1-subunit of a potassium channel (K-ATP) in pancreatic $\beta$ cells, 


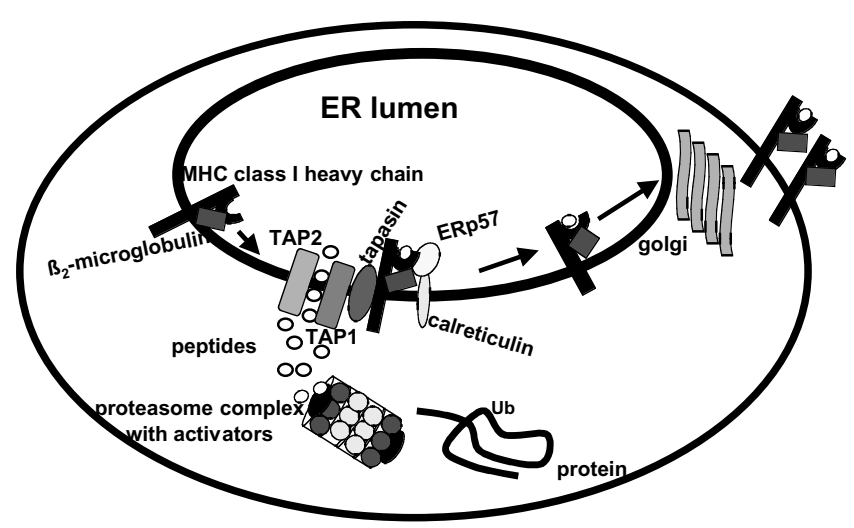

Fig. 1. The MHC class I antigen processing and presentation pathway. The classical MHC class I antigen processing and presentation pathway is divided into four major steps: (1) the generation of antigenic peptides by proteasomal degradation, (2) the ATP-dependent peptide transport from the cytosol in the ER via the TAP heterodimer, (3) the assembly of MHC class I HC, $\beta_{2}-\mathrm{m}$ and peptides, which is assisted by various chaperones (e.g., Erp57, tapasin and calreticulin), and (4) the export and presentation of the trimeric MHC/peptide complex.

which is mutated in congenital hyperinsulinism (11,12); the P-glycoproteins MDR1 and MDR3, which transport a series of hydrophobic drugs and phospholipids (13-15); and the peptide transporter TAP. TAP consists of two subunits, TAP1 and TAP2, and is the only $A B C$ transporter with a unique function in the immune system. Regarding sequence and topology, the $\mathrm{ABC}$ transporters possess significant homologies that are especially pronounced for the P-glycoproteins and TAP $(8,16)$.

\section{Structure and Function of TAP Molecules}

Genomic Organization of TAP The genomic structure of TAP has been well defined in different species, such as human, mouse, and rat (16-18). The genes of the human TAP1 and TAP2 subunits, which are located in the MHC class II locus of the chromosome

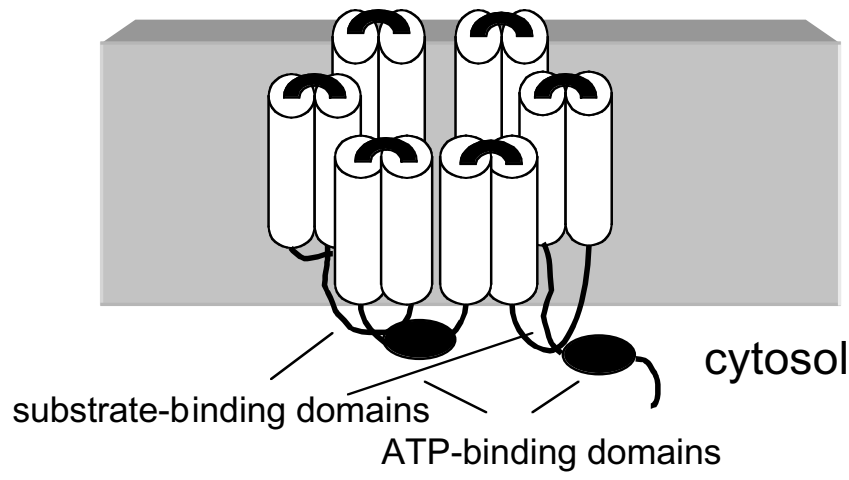

Fig. 2. Topology of typical ABC transporters. The schematic diagram of $\mathrm{ABC}$ transporters demonstrates the membrane topology with the polypeptide chains and the cytosolic substrateand ATP-binding domains.
6 and comprise 8-12 kilobase pairs, consist of 11 exons, each with a size of approximately 100-200 base pairs (bp). Exceptions are both exons 1, with sizes of 587 and $492 \mathrm{bp}$, respectively. TAP is evolutionary highly conserved with an approximately $35 \%$ homology between TAP1 and TAP2 in all species. Thus, the peptide transporter seems to have evolved from a common ancestor gene by duplication prior to the development of the adaptive immune system in vertebrates.

Topology of TAP Heterologous coexpression of TAP1 and TAP2 in insect cells or yeast suggest that the functional peptide transporter is a heterodimer consisting of the two subunits TAPl and TAP2. This model is further supported by the lack of peptide translocation in TAP1- or TAP2-negative (tumor) cells and TAP1-/- mice, as well as by restoration of TAP function upon TAP gene transfer (19-23). However, despite the sequence differences, TAP subunits of different species are capable of forming a functional TAP heterodimer $(24,25)$.

Using a number of different experimental approaches, the localization as well as the topology of TAP have been determined. Immune electron microscopy and confocal laser scanning microscopy have demonstrated an intracellular distribution of both TAP subunits in the ER (Fig. 3; 26,27), which is consistent with the localization, where MHC class I molecules are loaded with peptides (28).

Hydrophobicity analysis and sequence alignments of TAP proteins with other ABC transporters revealed that both TAP molecules span the ER membrane 6-10 times, containing a highly hydrophobic $\mathrm{N}$-terminal domain linked to the cytosolic nucleotide binding domains (NBT) including the conserved Walker A and Walker B motifs for NTP-binding and hydrolysis $(29,30)$.

Hypothetical TAP Models Using photocross-linking experiments with peptides, potential peptidebinding domains in both TAP subunits have been identified. Such analyses revealed similar binding regions for TAP1 and TAP2 composed of the cytosolic loops between the transmembrane (TM) regions-4 and TM-5 and a carboxy-terminal stretch of about 15 amino acids following TM-6. This topology model suggested that these regions are exposed to the cytosol (31).

Recently, Voss et al. (32) developed another topology model for TAP employing a series of Cterminal deletions for TAP1 and TAP2 subunits. As shown in Figure 4a, TAP1 and TAP2 consist of 8 and 7 transmembrane domains, respectively. Thus, the $\mathrm{N}$-and C-terminal domain of TAPl as well as the Cterminal domain of TAP2 is located in the cytosol, whereas the N-terminus of TAP2 is located in the ER. The pore-forming domains of the TAP subunits are aligned in a head-head/tail-tail orientation (33; Fig. 4b), which is followed by a cytosolic potential 


\section{A: Calnexin}

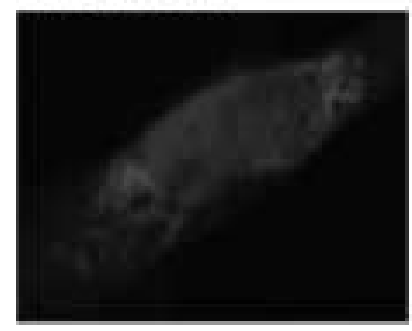

B: TAP-negative

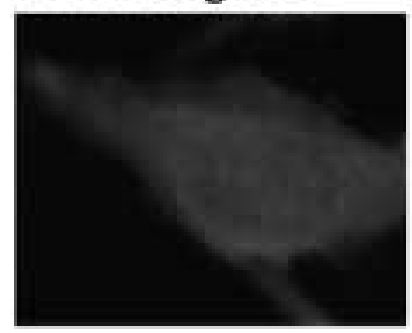

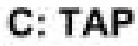

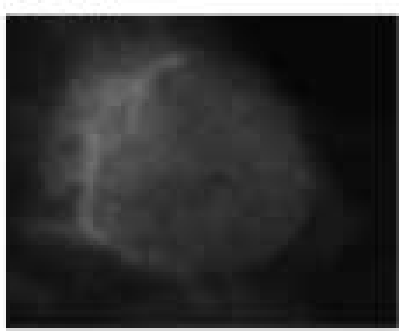

Fig. 3. ER localization of TAP. (A and B) TAP-negative cells were stained either with an anti-calnexin antibody (red color, A) or the anti-TAPl monoclonal antibody mAbl48.3 (B). (C) TAP overexpressing cells were stained with the anti-TAPl monoclonal antibody mAb 148.3 (green color). TAP staining is comparable to calnexin staining, suggesting that TAP1 expression is localized in the ER.

peptide-binding domain and subsequently by the C-terminal domain containing the NTP-binding sites. Deletions of 20 or fewer amino acids (aa) in the potential peptide-binding domain of the TAPl subunit defined regions between amino acids 366-405 that are essential for proper peptide transporter function, whereas deletions of other regions (aa 345-365 and aa 465-487) did not influence TAP activity (34). Although many different approaches have been employed to characterize the structure, organization, and functional domains in TAP, the topology of TAP, the domains responsible for peptide binding and for peptide transport, as well as the interaction between the TAPl and TAP2 subunits are controversially discussed and require further investigations.

Peptide Selectivity of TAP During the last decade, the substrate specificity of TAP has been well studied by a number of groups employing a peptide translocation assay that traps transported peptides in the ER via glycosylation (35). Information is available about the length and sequence preferences of the transported peptides (36-39). Peptides with a length of 8-16 aa are preferentially transported by TAP, although longer peptides $(>40$ aa) are also transported, but with a lower efficiency (40). In contrast to the peptide transporter assay, the use of
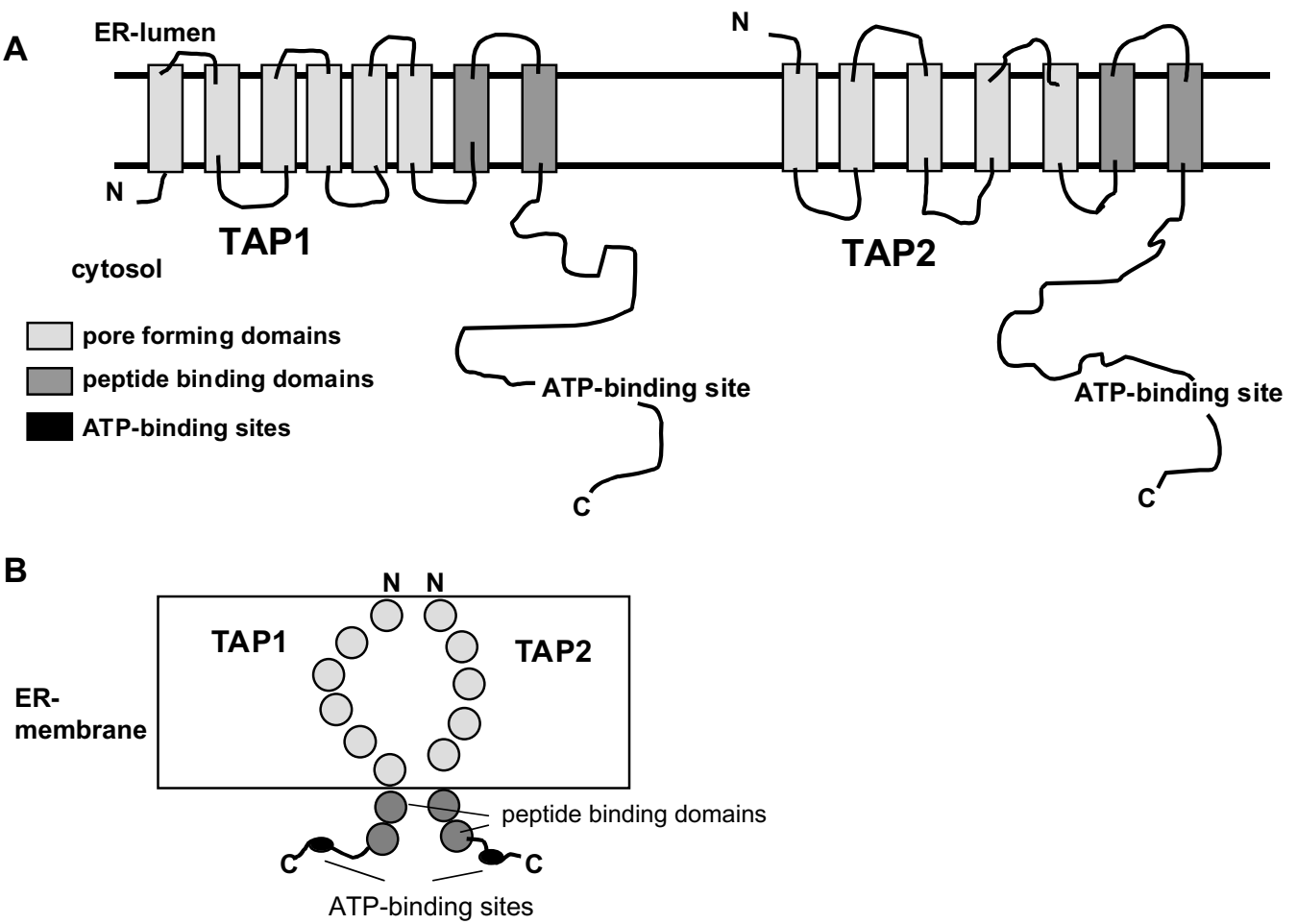

Fig. 4. The putative TAP model by Voss et al. (32). (A) Membrane topology of TAP. The light gray regions represent the transmembrane domains, the dark gray regions indicate potential peptide-binding domains, and the regions marked in black represent the ATP-binding sites. (B) The head-head/tail-tail orientation of TAP1 and TAP2 in the ER membrane shown from the ER in top view forming a pore for peptide translocation. 
peptide-binding assays allows a more accurate analysis of substrate specificity. The contribution of each peptide residue to the affinity for TAP was determined by screening combinatorial peptide libraries and determined the influence of a single peptide residue independent of a given sequence context on the affinity of TAP (41). These experiments suggest that the carboxy-terminal aa and the first three amino-terminal residues play a key role in peptide selectivity of TAP. Murine TAP alleles selectively transport peptides with a hydrophobic C-terminus, whereas human TAP complexes transport both peptides with a hydrophobic C-terminus and peptides with a basic C-terminus $(37,39,42,43)$. The selectivity of TAP is important because it mostly transports peptides matching to MHC class I molecules.

Mechanism of Peptide Transport Peptide transport by TAP is a multistep process (44). First, peptides associate with TAP in an ATP-independent manner $(45,46)$. This step determines the peptide selectivity and is followed by a slow isomerization of the TAP complex. The structural reorganization of the molecule triggers peptide translocation across the membrane, which is ATP dependent (47).

Peptides with a low affinity to MHC class I molecules are transported into the ER, but are not rapidly loaded onto MHC class I molecules (48). Thus, they are available for export out of the ER into the cytosol via the Sec6l channel (49).

Biochemical Modifications of TAP TAP1 and TAP2 are mainly nonglycosylated, although three putative glycosylation sites, two facing the cytosol and one placed in the ER, have been identified (26). Recently, it has been demonstrated that the TAP subunits are phosphorylated under physiologic conditions. They form a high molecular complex with tapasin, MHC class I heavy chain, and a putative phosphatase, which dephosphorylates the complex. This dephosphorylation process is essential for proper TAP function, because phosphorylated TAP is not capable of transporting peptides into the ER, suggesting that an altered phosphorylation status of TAP may represent an immune escape mechanism (50).

\section{Modulation of TAP Expression}

Promoters of the TAP Genes The potential promoters of both TAP genes contain no TATA motifs in the 5' flanking sequence, but putative GC-rich elements containing SPl-binding sites either 128 or $70 \mathrm{nu}-$ cleotides upstream of the translation start codon for TAP1 and TAP2, respectively (51). These are at least essential for proper activity of the TAP1 promoter (52). The human TAPl promoter is a bidirectional promoter consisting of 593 bp, which also coordinately regulates the low-molecular-weight protein (LMP)2. It contains an IFN- $\gamma$ and a p53 response element, as well as a NF- $\kappa \mathrm{B}$-binding site
$(53,54)$. The latter is important for the tumor necrosis factor (TNF)- $\alpha$-mediated induction of TAPI and LMP2 transcription (52). In contrast to the TAP1 promoter, the human TAP2 promoter still has to be characterized in detail.

Regulation of TAP Expression by Cytokines With a few exceptions, most cell types constitutively express MHC class I surface molecules. However, the MHC class I expression can be strongly enhanced by various cytokines, such as IFN- $\alpha$, IFN-, TNF- $\alpha$ or granulocyte-macrophage colony stimulating factor (GMCSF). Analogous to MHC class I molecules, TAPI and TAP2 subunits are upregulated by IFNs and TNF- $\alpha$, but with distinct time kinetics and to a different extent (55-57). TAP1 and TAP2 transcription is rapidly upregulated after IFN- $\gamma$ treatment consecutively increasing over 48 hours to 10 - to 20 -fold, whereas the IFN- $\gamma$-mediated induction of the human leukocyte antigen (HLA) class I heavy chain transcription occurs more slowly and later, increasing only 10-fold in 48 hours. Although most cytokines enhance TAP expression, interleukin (IL)-10 causes a downregulation of both transcription and translation of the peptide transporter, thereby abrogating its function $(58,59)$. The IL-10-mediated downregulation of TAP leads to reduced cell surface expression of MHC class I antigens (59). The inhibitory effect of IL10 may have in vivo relevance, because various tumors secrete IL-10. Results with murine IL-10 transduced cells suggest that IL-10 production decreases TAP function, which is accompanied by low levels of MHC class I surface expression and reduced CTLspecific lysis, but enhances sensitivity to natural killer cell-mediated cytotoxicity (58).

\section{TAP Polymorphism, Functional Significance, and Association With Autoimmune Disease}

Several alleles of human TAP1 and TAP2 have been identified in different populations, but their influence on TAP activity and/or peptide-binding specificity varies $(60,61)$. A functional polymorphism was found for a human TAP2 splice variant (TAP2iso) that consists of an altered C-terminus. When compared to the wild-type TAP1/TAP2, the TAP1-TAP2iso heterodimer exhibited a distinct peptide selectivity, transporting peptides with hydrophobic C-terminal residues 30 times more efficiently (62), thereby creating a new pattern of presented peptides/antigens. To the best of our knowledge, other functional TAP polymorphisms have only been detected in the rat $(38,63)$.

Susceptibility to transplant rejection and autoimmune diseases such as type I diabetes and rheumatoid arthritis are associated with HLA defects and polymorphisms $(64,65)$. Whether there exists an association between these diseases and TAP polymorphism is controversial (66). Höhler et al. (67) described an association between TAP1 (but not TAP2) polymorphism and rheumatoid arthritis; other au- 
thors failed to detect any correlation (68-70). Similar discrepancies between association of type I diabetes, multiple sclerosis, and Grave's disease and rejection of renal transplants with TAP polymorphism have been found by various groups (71-77). However, the deficiencies of HLA class I presentation in lymphoid cells from individuals with type I diabetes was corrected by TAP transfection (78).

\section{Human Diseases Associated With Dysfunction of TAP: Clinical Relevance?}

Any effect that impairs the TAP-mediated peptide translocation into the ER results in reduced MHC class I surface expression. Thus, cells with a defective MHC class I antigen processing and presentation pathway can be identified by measuring the MHC class I surface expression, which can be either downregulated or totally lost. The molecular defects underlying the abnormalities of MHC class I and TAP expression in human diseases as well as the role of TAP deficiencies for immune response have only been addressed to a limited extent. However, this information is important; it might contribute both to our understanding of the basis of immune escape mechanisms in diseases as well as to the design or optimization of the treatment of patients with TAP defects.

Genetic Diseases Bare lymphocyte syndrome (BLS) is characterized by a severe downregulation of MHC class I or class II antigens. BLS is divided into two subtypes. In type I BLS, the defect is confined to the MHC class I molecules, whereas in type II BLS, MHC class II cell surface expression is downregulated (79). Only a small number of patients with type I BLS have been identified worldwide, which could be differentiated into three disease subsets depending on their clinical and immunologic appearance. For example, one group of BLS patients (10 patients from 7 families) exhibits defective TAP expression and has similar clinical manifestations, including bacterial and viral infections (sinusitis, chronic bronchitis) and necrotizing granulomatous skin lesions (80). In these BLS patients, structural alterations have been found in both TAP1 and TAP2 subunits (81-84). The mutations lead to the generation of a premature stop codon resulting in nonfunctional TAP proteins $(81,85)$. Interestingly, mutations in the TAP2 subunit result in a more severe disease than mutations in the TAPl subunit (80).

The lymphocyte repertoire of peripheral blood displayed low numbers of $\mathrm{CD}^{+} \alpha \beta$ T cells, but an expansion of NK and $\gamma \delta$ T cells in most BLS patients (86). The NK and $\gamma \delta$ T cells may be involved both in the pathogenesis of granulomatous skin lesions and in antiviral immune responses that do not require TAP-dependent antigen processing $(80,83)$.

Viral Infections and Viral Persistence: Transcriptional and Posttranscriptional Regulation $\mathrm{CD}^{+} \mathrm{CTL}$ efficiently recognize and eliminate virus-infected cells (87), a process that requires the presentation of viral peptide fragments in the context of MHC class I molecules on the cell surface. Persistent viruses, such as herpes simplex virus (HSV), human cytomegalovirus (HCMV), adenoviruses (Ad), and human papilloma virus (HPV) have been forced to develop a series of strategies to evade immune defense by interfering with various steps of the antigen processing and representation pathway. Some directly affect TAP expression and/or function, resulting in defects in MHC class I cell surface expression and immune responses (88; summarized in Fig. 5).

The immediate early protein ICP47 encoded by the HSV type 1 (HSV-1) is responsible for the downregulation of MHC class I surface expression in human fibroblasts, which is accompanied by a lack of CTL response. ICP47 binds with high affinity to the peptide-binding site of TAP, thereby destabilizing TAP and inhibiting the TAP-mediated peptide transport into the ER (89-91). The interaction of human ICP47 and the TAP complex is species specific because ICP47 has a 100-fold higher affinity for human than for murine TAP (92). The identification of the critical amino acids of ICP47 responsible for inhibition of TAP function represents the basis for the development of therapeutic drugs. These may be applicable in novel vaccination strategies against HSV owing to restoration of CTL-mediated recognition of virus-infected cells.

The HCMV encodes the ER-resident glycoprotein gpUS6 that inhibits the TAP-mediated peptide transport due to its binding to the ER luminal part of the TAP complex (93-95). This results in a conformational change of TAP. Moreover, HCMV inhibits dephosphorylation of TAP, which results in lack of peptide transport and impaired MHC class I surface expression (50). Furthermore, another member of the herpes virus family, the pseudorabies virus (PRV), interferes and inhibits the porcine pep-

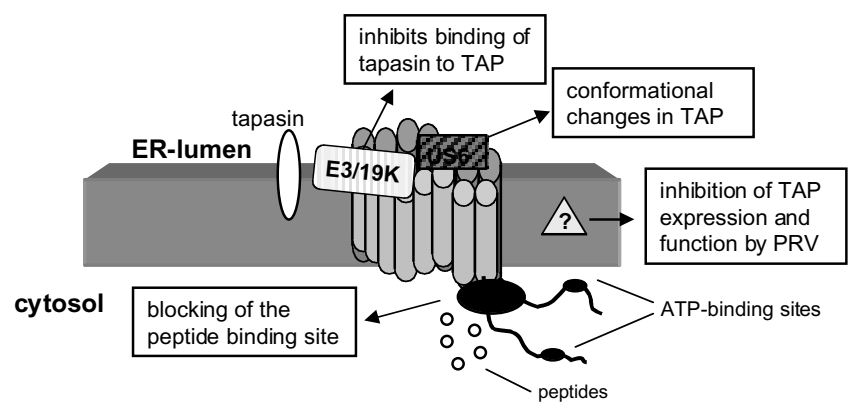

Fig. 5. Viral interference with TAP function. The major mechanisms of viral proteins interfering with TAP function are schematically represented. ICP47 (HSV) blocks the peptidebinding site of TAP, US6 (CMV) induces conformational changes of TAP by binding to it in the ER lumen, and Ad E3gp 19K inhibits tapasin binding to TAP, thereby blocking the association of MHC class I HC with TAP. PRV interferes with TAP, thereby inhibiting its function; the exact mechanism is unknown. 
tide transporter function resulting in MHC class I deficiencies (96).

Not only the herpes viruses but also human Ad have been shown to affect TAP function $(97,98)$. This could be either due to transcriptional downregulation of TAP expression or binding of the adenoviral protein E3gp19K to TAP, thereby inhibiting complex formation with tapasin, further preventing MHC class I/TAP association (98). In contrast to human Ad virus, infection of mouse cells with murine Ad virus does not influence MHC class I surface expression (99).

It has been known for a long time that cervical cancer and respiratory papillomatosis are diseases of viral origin caused by the infection of different types of HPV. MHC class I surface expression was variably downregulated in both diseases, which was associated with decreased TAPl expression $(100,101)$. In addition, the level of TAPI and MHC class I antigen expression correlated inversely with disease recurrence $(100,102)$. The E7 early proteins of HPV types 6 and 18, essential for the maintenance of respiratory papillomas (RRP) and cervical cancer, respectively, repress the bidirectional LMP2/TAP1 promoter, which could be responsible for low MHC class I surface expression in these diseases (103). These findings suggest that viruses may evade $\mathrm{T}$-cell recognition and killing of infected cells by decreasing MHC class I surface expression through modulation of TAP. However, it is speculated that additional viruses that influence the antigen-processing pathway, including the peptide transporter activity, will be identified.

Impaired TAP Expression and Function Tumors of Distinct Histology: Sequence Alterations and Dysregulation Analysis of both surgically removed lesions and cell lines derived from tumors of distinct histology has provided evidence that neoplastic transformation is frequently associated with impaired TAP expression $(23,104)$. However, most investigations have been restricted to the analysis of TAPI expression because of the limited availability of anti-TAP2 antibodies. In comparison to autologous normal tissues, TAPl downregulation or loss was found in all tumor types analyzed with a frequency ranging from $10-84 \%$ (23). Similar results were obtained by analysis of tumor cell lines (Table 1). The clinical impact of TAP deficiencies by malignant cells varies among tumors. The frequency of TAPI downregulation was more pronounced in metastatic than in primary lesions in breast, cervical, colon, small cell lung carcinomas (SCLC), and melanomas, whereas deficient TAP expression of renal cell carcinomas (RCC) is not correlated with tumor grading and staging (104-108). In melanoma, impaired TAP expression is also associated with poor prognosis and reduced survival rate (107). Heterogeneity in terms of quantity and quality of TAP downregulation among various types of tumors (lesions/cell lines) has been detected, which might reflect differences in the patient populations selected for analysis, immunobiology of the tumor types, the proliferative status of the tumor cells, and the sensitivity of the techniques employed (109).

Although impaired TAP expression is frequently found in tumors of distinct origin, the underlying molecular mechanisms of these TAP deficiencies have not yet been defined. Consequently, until recently, tumor lesions/cell lines have not been monitored for TAP mutations. In one lung cell carcinoma cell line, a new TAP1 allele has been identified that results in expression of a nonfunctional TAP protein (110). In addition, a bp deletion in the TAPI subunit of a melanoma cell line also results in TAP dysfunction

Table 1. TAP downregulation in lesions and cell lines derived from human tumors of distinct histology

Downregulation of Expression (\%)

\begin{tabular}{|c|c|c|c|c|c|c|}
\hline \multirow[b]{2}{*}{ Tumor Type } & \multirow[b]{2}{*}{ Samples $(n)$} & \multicolumn{2}{|c|}{ Primary Lesions } & \multirow[b]{2}{*}{ Samples $(n)$} & \multicolumn{2}{|c|}{ Cell Lines } \\
\hline & & TAP1 & TAP2 & & TAP1 & TAP2 \\
\hline Breast carcinoma & 63 & $13-44$ & 21 & ND & ND & ND \\
\hline SCLC & 93 & 38 & ND & 6 & 100 & 100 \\
\hline Colon carcinoma & 81 & 14 & ND & 5 & 32 & 23 \\
\hline $\mathrm{RCC}$ & 70 & 52 & ND & 19 & 79 & 74 \\
\hline Cervical carcinoma & 76 & 49 & ND & 7 & 0 & 0 \\
\hline Melanoma & 53 & 31 & 16 & 9 & 33 & 57 \\
\hline
\end{tabular}

ND, not determined.

Results are expressed as percent downregulation of TAP1 and TAP2 expression when compared to respective controls and have been recently summarized by Seliger et al. (23). 
accompanied by abnormalities of MHC class I surface expression (Seliger et al. submitted). Transfection of these melanoma cells with wild-type TAP1 restores peptide transport as well as MHC class I surface expression. In contrast, a large number of RCC lesions with deficient TAP expression demonstrated neither mutations nor deletions in TAP (Seliger et al., submitted). Because correction of reduced TAP expression can be achieved in many tumor cells of different origin by cytokine treatment, TAP abnormalities mainly appear to be due to defects in regulatory mechanisms rather than structural alterations $(23,111,112)$. This hypothesis is further supported by recent data from $\mathrm{Zhu}$ et al. (54) demonstrating that p53 as well as DNA damaging agents enhance TAPI expression. Because more than $50 \%$ of human tumors exhibit mutations of the p53 tumor suppressor gene, it is anticipated that these p53 mutations abrogate immune surveillance. Thus, dysfunctional p53 is not capable to induce TAP1 upon genotoxic stress (54).

The impact of TAP abnormalities on the recognition of tumor cells by $\mathrm{CD}^{+}$CTL has only been investigated in a few cases utilizing tumor cell lines, surrogate antigens, and HLA class I-restricted antigen-specific CTL (112). A correlation between the degree of TAP downregulation, impaired MHC class I surface expression, and the recognition of tumor cells by tumor antigen-specific MHC class I-restricted cells has been found $(23,113)$. These results further suggest a negative impact of deficient TAP expression on the outcome of T-cell-based immunotherapy, although $\mathrm{CD}^{+} \mathrm{CTL}$ that specifically recognize TAP-negative cells have been identified (114).

\section{Conclusions and Unanswered Questions}

The heterodimeric peptide transporter complex TAP plays a key role in proper antigen processing and presentation. The knowledge of its detailed molecular structure and function will contribute to our understanding of the physiologic and pathophysiologic processes in which the TAP complex is involved. However, there exist still many open questions regarding the general mechanisms of $\mathrm{T}$ cell immunity. The peptide binding to MHC class I molecules in the ER appears to represent one important process for T-cell-mediated immune responses.

Elucidation of the distinct steps of the antigen processing pathway is essential for the determination of its role in various malignancies, such as autoimmune diseases, cancer, and viral infections. Characterization of the expression pattern and the underlying molecular mechanisms of APM deficiencies including TAP will help to clarify the host/ tumor interaction and the significance of TAP dysfunction in this process. In addition, it will lead to the design and/or optimization of vaccination strategies concerning viral infections and tumors as well as to the development of innovative therapeutic approaches for autoimmune diseases.

\section{Acknowledgement}

We thank Dr. Dennis Strand, I. Medical Clinic, Johannes-Gutenberg-University, Mainz for his help regarding the immunfluorescence analysis and Mrs. I. Schmidt for help in preparing the manuscript.

\section{References}

1. Ortmann B, Copeman J, Lehner PJ, et al. (1997) A critical role for tapasin in the assembly and function of multimeric MHC class I-TAP complexes. Science 277: 1306-1309.

2. Spee P, Neefjes J. (1997) TAP-translocated peptides specifically bind proteins in the ER, including gp96, protein disulfide isomerase and calreticulin. Eur. J. Immunol. 27: 1441-2449.

3. Suh W, Mitchell E, Yang Y, Peterson P, Waneck G, Williams DB. (1996) MHC class I molecules form ternary complexes with calnexin and TAP and undergo peptide regulated interaction with TAP via their extracellular domains. J. Exp. Med. 184: 337-348.

4. Sadasivan B, Lehner PJ, Ortmann B, Spies T, Cresswell P. (1996) Roles for calreticulin and a novel glycoprotein, tapsin, in the interaction of MHC class I molecules with TAP. Immunity 5: 103-114.

5. Grandea AG, Golovina TN, Hamilton SE, et al. (2000) Impaired assembly yet normal trafficking of MHC class I molecules in tapasin mutant mice. Immunity 13: 213-222.

6. Pamer E, Cresswell P. (1998) Mechanism of MHC class Iresticted antigen processing. Annu. Rev. Immunol. 16: 323-358.

7. van Endert PM. (1999) Genes regulating MHC class I processing of antigen. Curr. Opin. Immunol. 11: 82-88.

8. Higgins CF. (1992) ABC transporters: from microorganisms to man. Annu. Rev. Cell Biol. 8: 67-113.

9. Anderson MP, Gregory RJ, Thompson S, et al. (1991) Demonstration that CFTR is a chloride channel by alteration of its anion selectivity. Science 98: 202-205.

10. Riordan JR, Chang XB. (1992) CFTR, a channel with the structure of a transporter. Biochim. Biophys. Acta 1101: 221-222.

11. Aguilar-Bryan L, Clement JP, Nelson DA. (1998) Sulfonylurea receptors and ATP-sensitive potassium ion channels. Methods Enzymol. 292: 732-744.

12. Meissner T, Brune W, Mayatepek E. (1997) Persistent hyperinsulinaemic hypoglycaemia of infancy: therapy, clinical outcome and mutational analysis. Eur. J. Pediatr. 156: 754-757.

13. Gottesman MM, Pastan I. (1993) Biochemistry of multidrug resistance mediated by the multidrug transporter. Annu. Rev. Biochem. 62: 385-427.

14. Saeki T, Ueda K, Tanigawara Y, Hori R, Komano T. (1993) Human P-glycoprotein transports cyclosporin A and FK506. J. Biol. Chem. 268: 6077-6080.

15. Saeki T, Ueda K, Tanigawara Y, Hori R, Komano T. (1993) Pglycoprotein-mediated transcellular transport of MDRreversing agents. FEBS Lett. 324: 99-102.

16. Powis SH, Mockridge I, Kelly A, et al. (1992) Polymorphism in a second ABC transporter gene located within the class II region of the human major histocompatibility complex. Proc. Natl. Acad. Sci. USA 89: 1463-1467.

17. Spies T, Bresnahan M, Bahram S, Arnold D, Blanck G, Mellins E. (1990) A gene in the human major histocompatibility complex class II region controlling the class I antigen presentation pathway. Nature 348: 744-747.

18. Trowsdale J, Hanson I, Mockridge I, Beck S, Townsend A, Kelly A. (1990) Sequence encoded in the class II region of the MHC related to the ABC superfamily of transporters. $\mathrm{Na}$ ture 348: 741-743. 
19. Ljunggren HG, Stam N, Öhlen C, et al. (1990) Empty class I molecules come out in the cold. Nature 346: 476-480.

20. Spies T, DeMars R. (1991) Restored expression of MHC class I molecules by gene transfer of a putative peptide transporter. Nature 351: 323-324.

21. Powis SJ, Townsend AR, Deverson EV, Bastin J, Butcher GW, Howard JC. (1991) Restoration of antigenic presentation to the mutant cell line RMA-S by an MHC-linked transporter. Nature 354: 528-531.

22. van Kaer L, Ashton-Rickardt PG, Ploegh HL, Tonegawa S. (1992) TAPI mutant mice are deficient in antigen presentation, surface class I molecules, and $\mathrm{CD}^{-} 8^{+} \mathrm{T}$ cells. Cell 71: 1205-1209.

23. Seliger B, Maeurer MJ, Ferrone S. (2000) Antigen processing machinery break-down and tumor growth. Immunol. Today 21: 455-464.

24. Armandola E, Momburg F, Nijenhuis M, Bulbuc N, Früh K, Hämmerling GJ. (1996) A point mutation in the human transporter associated with antigen processing (TAP2) alters peptide transport specificity. Eur. J. Immunol. 26: 17481755.

25. Yewdell JW, Esquivel F, Arnold D, Spies T, Eisenlohr LC, Bennink JR. (1993). Presentation of numerous viral peptides to mouse MHC class I-restricted T lymphocytes is mediated by the human MHC-encoded transporter or a hybrid mouse-human transporter. J. Exp. Med. 177: 1785-1789.

26. Meyer T, van Endert PM, Uebel S, Ehring B, Tampé R. (1994) Functional expression and purification of the ABC transporter complex associated with antigen processing (TAP) in insect cells. FEBS Letters 351: 443-447.

27. Russ G, Esquivel F, Yewdell JW, Cresswell P, Spies T, Bennink JR. (1995) Assembly, intracellular location and nucleotide binding properties of the human peptide transporters TAP1 and TAP2 expressed by recombinant vaccinia virus. J. Biol. Chem. 270: 21312-21318.

28. Kleijmeer MJ, Kelly Y, Geute HJ, Slot JW, Townsend A, Trowsdale J. (1992) Location of MHC-encoded transporters in the endoplasmic reticulum. Nature 357: 342-344.

29. Walker JE, Saraste M, Runswick MJ, Gay NJ. (1982) Distantly related sequences in the alpha and beta subunits of ATP synthase, myosin, kinases and other ATP-requiring enzymes and a common nucleotide binding fold. $E M B O \mathrm{~J}$. 1: 945-951.

30. Monaco JJ, Cho S, Attaya M. (1990) Transport protein genes in the murine MHC: possible implications for antigen processing. Science 250: 1723-1726.

31. Nijenhuis M, Hämmerling GJ. (1996) Multiple regions of the transporter associated with antigen processing (TAP) contribute to its peptide binding site. J. Immunol. 157: 5467-5472.

32. Voss JC, Spee P, Momburg F, Neefjes JJ. (1999) Membrane topology and dimerization of the two subunits of the transporter associated with antigen processing reveal a three domain structure. J. Immunol. 163: 6679-6685.

33. Vos JC, Reits EA, Wojcik-Jacobs E, Neefjes JJ. (2000) Subunit interactions visualized by post-translational translocation and ER-mobility indicate a head-head/tail-tail orientation for the pore of the ABC transporter TAP. Curr. Biol. 13: 1-7.

34. Ritz U, Momburg F, Huber C, Pircher HP, Seliger B. (2001) Identification of domains in the human peptide transporter subunit TAPI required for TAP function. Int. Immunol. 13: 31-41.

35. Neefjes JJ, Momburg F, Hämmerling GJ. (1993) Selectivity and ATP-dependent translocation of peptides by the MHCencoded transporter. Science 261: 769-771.

36. Heemels MT, Ploegh HL. (1994) Substrate specificity of allelic variants of the TAP peptide transporter. Immunity $\mathbf{l}$ : 775-779.

37. Momburg F, Roelse J, Hämmerling G, Neefjes J. (1994) Peptide size selection by the major histocompatibility complexencoded peptide transporter. J. Exp. Med. 179: 1613-1618.

38. Momburg F, Armandola E, Post M, Hämmerling GJ. (1996) Residues in TAP2 peptide transporters controlling substrate specificity. J. Immunol. 156: 1756-1759.
39. Neefjes J. Gottfried E, Roelse J, Grommé M, Obst R, Hämmerling GJ, Momburg F. (1995) Analysis of fine specificity of rat, mouse and human TAP peptide transporters. Eur. J. Immunol. 25: 1133-1136.

40. Koopmann JO, Post M, Neefjes JJ, Hämmerling GJ, Momburg F. (1996) Translocation of long peptides by transporters associated with antigen processing (TAP). Eur. J. Immunol. 26: 1720-1724.

41. Uebel S, Meyer TH, Kraas W, Kienle S, Jung G, Wiesmüller KH, Tampé R. (1995) Requirement for peptide binding to the human transporter associated with antigen processing revealed by peptide scans and complex peptide libraries. $J$. Biol. Chem. 270: 18512-18516.

42. Neisig A, Wubbolts R, Zang X, Melief C, Neefjes JJ. (1996) Allele-specific differences in the interaction of MHC class I molecules with transporter associated with antigen processing. J. Immunol. 156: 3196-3400.

43. Uebel S, Kraas W, Kienle S, Wiesmüller KH, Jung G, Tampé R. (1997) Recognition principle of the TAP transporters disclosed by combinatorial peptide libraries. Proc. Natl. Acad. Sci. USA 94: 8976-8982.

44. van Endert PM, Tampé R, Meyer TH, Tisch R, Bach FJ, McDevitt HO. (1994) A sequential model for peptide binding and transport by the transporters associated with antigen processing. Immunity 1: 4591-500.

45. van Endert PM, Riganelli D, Greco G, Fleischauer K, Sette A, Bach JF. (1995) The peptide-binding motif of the human transporter associated with antigen processing. J. Exp. Med. 182: 1883-1895.

46. Androlewicz M, Cresswell P. (1994) Human transporters associated with antigen processing possess a promiscuous peptide-binding site. Immunity 1: 7-14.

47. Knittler MR, Alberts P, Deverson EV, Howard JC. (1999) Nucleotide binding by TAP mediates association with peptide and release of assembled MHC class I molecules. Curr. Biol. 9: 999-1008.

48. Androlewicz M, Ortmann B, van Endert P, Spies T, Cresswell P. (1994) Characteristics of peptide and major histocompatibility complex class $\mathrm{I} / \beta^{2}$-microglobulin binding to the transporter associated with antigen processing (TAPl and TAP2). Proc. Natl. Acad. Sci. USA 91: 12716-12720.

49. Koopmann JO, Albring J, Hüter E, et al. (2000) Export of antigenic peptides from the endoplasmic reticulum intersects with retrograde protein translocation through the Sec6lp channel. Immunity 13: 1-20.

50. Li Y, Salter-Cid L, Vitiello A, et al. (2000) Regulation of transporter associated with antigen processing by phosphorylation. J. Biol. Chem. 275: 24130-24135.

51. Beck S, Kelly A, Radley E, Kurshid F, Alderton RP, Trowsdale J. (1992) DNA sequence analysis of $66 \mathrm{~kb}$ of the human MHC class II region encoding a cluster of genes for antigen processing. J. Mol. Biol. 228: 433-441.

52. Wright KL, White LC, Kelly A, Beck S, Trowsdale J, Ting JP. (1995) Coordinate regulation of the human TAP1 and LMP2 genes from a shared bidirectional promoter. J. Exp. Med. 181: 1459-1471.

53. Chatterjee-Kishore M, Kishore R, Hicklin DJ, Marincola FM, Ferrone S. (1998) Different requirement for signal transducer and activator of transcription $1 \alpha$ and interferon regulatory factor 1 in the regulation of low molecular mass polypeptide 2 and TAP1 gene expression. J. Biol. Chem. 273: 16177-16183.

54. Zhu K, Wang J, Zhu J, Jiang J, Shou J, Chen X. (1999) p53 induces TAPl and enhances the transport of MHC class I peptides. Oncogene 18: 7740-7747.

55. Epperson DE, Arnold D, Spies T, Cresswell P, Pober JS, Johnson DR. (1993) Cytokines increase transporter in antigen processing-1 expression more rapidly than HLA class I expression in endothelial cells. J. Immunol. 149: 32973301.

56. Min W, Pober JS, Johnson DR. (1996) Kinetically coordinated induction of TAPI and HLA class I by IFN-gamma. J. Immunol. 156: 3174-3183. 
57. Seliger B, Hammers S, Höhne A, Zeidler R, Knuth A, Gerharz CD, Huber C. (1997) IFN- $\gamma$-mediated coordinated transcriptional regulation of the human TAP-1 and LMP-2 genes in human renal cell carcinoma. Clin. Cancer Res. 3: 573-578.

58. Petersson M, Charo J, Salazar-Onfray F, et al. (1998) Constitutive IL-10 production accounts for the high NK sensitivity, low MHC class I expression, and poor transporter associated with antigen processing (TAP)-1/2 function in the prototype NK target YAC-1. J. Immunol. 161: 2099-2105.

59. Zeidler R, Eissner G, Meissner P, Uebel S, Tampé R, Lazis S, Hammerschmidt W. (1997) Downregulation of TAPl in B lymphocytes by cellular and Epstein-Barr virus-encoded interleukin-10. Blood 90: 2390-2397.

60. Obst R, Armandola EA, Nijenhuis M, Momburg F, Hämmerling GJ. (1995) TAP polymorphism does not influence transport of peptide variants in mice and humans. Eur. J. Immunol. 25: 2170-2176.

61. Rueda-Faucz FR, Macagnan-Probst C, Petzl-Erler ML. (2000) Polymorphism of LMP2, TAP1, LMP7 and TAP2 in Brazilian amerindians and caucasoids: implications for the evolution of allelic and haplotypic diversity. Eur. J. Immunogenet. 27: 5-16.

62. Yan G, Shi L, Faustmann D. (1999) Novel splicing of the human MHC-encoded peptide transporter confers unique properties. J. Immunol. 162: 852-856.

63. Deverson EV, Leong L, Seelig A, Coadwell WJ, Tredgett EM, Butcher GW, Howard JC. (1998) Functional analysis by sitedirected mutagenesis of the complex polymorphism in rat transporter associated with antigen processing. J. Immunol. 160: 2767-2779.

64. Faustman D, Li XP, Lin HY, Fu YE, Eisenbarth G, Avruch J, Guo J. (1991) Linkage of faulty major histocompatibility complex class I to autoimmune diabetes. Science 254: 1756-1761.

65. Fu Y, Yan G, Shi L, Faustman D. (1998) Antigen processing and autoimmunity. Evaluation of mRNA abundance and function of HLA-linked genes. Ann. N.Y. Acad. Sci. 842: 138-155.

66. van Endert PM, Lopez MT, Patel SD, Monaco JJ, McDevitt HO. (1992) Genomic polymorphism, recombination, and linkage equilibrium in human major histocompatibility complex-encoded antigen-processing genes. Proc. Natl. Acad. Sci. USA 89: 11594-11597.

67. Hohler T, Weimann A, Schneider PM, et al. (1996) TAPpolymorphism in juvenile onset psoriasis and psoriatic arthritis. Hum. Immunol. 51: 49-54.

68. Singal DP, Ye M, Qiu X, D'Souza M. (1994) Polymorphisms in the TAP-2 gene and their association with rheumatoid arthritis. Clin. Exp. Rheumatol. 12: 29-33.

69. Vandevyver C, Geusens P, Cassiman JJ, Raus J. (1995) Peptide transporter genes (TAP) polymorphisms and genetic susceptibility to rheumatoid arthritis. Br. J. Rheumatol. 34: 207-214.

70. Vejbaesya S, Luangtrakool P, Luangtrakool K, Sermduangprateep C, Pasivisutt L. (2000) Analysis of TAP and HLADM polymorphism in Thai rheumatoid arthritis. Hum. Immunol. 61: 309-313.

71. Cucca F, Congia M, Trowsdale J, Powis SH. (1994) Insulindependent diabetes mellitus and the major histocompatibility complex peptide transporters TAP1 and TAP2: no association in a population with a high disease incidence. Tissue Antigens 44: 234-240.

72. Chevrier D, Giral M, Braud V, Bourbigot B, Muller JY, Bignon JD, Soulillou JP. (1995) Effects of MHC-encoded TAP1 and TAP2 gene polymorphism and matching on kidney graft rejection. Transplant. 60: 292-296.

73. Kobayashi T, Yokoyama I, Inoko H, et al. (2000) Significance of transporter associated with antigen processing gene polymorphism in living renal transplantation. Hum. Immunol. 61: 670-674.

74. Kawaguchi Y, Ikegami H, Fukuda M, Takekawa K, Fujioka Y, Fuji Ueda H, Ogihara T. (1994) Absence of association of TAP and LMP genes with type I (insulin-dependent) diabetes mellitus. Life Sci. 54: 2049-2053.
75. Ma L, Penfornis A, Wang X, et al. (1997) Evaluation of TAPI polymorphism with insulin dependent diabetes mellitus in Finnish diabetic patients. Hum. Immunol. 53: 159-166.

76. Rau H, Nicolay A, Usadel KH, Finke R, Donner H, Walfish PG, Badenhoop K. (1997) Polymorphism of TAPl and TAP2 genes in Graves disease. Tissue Antigens 49: 16-22.

77. Vandevyver C, Stinissen P, Cassiman JJ, Raus J. (1994) TAP1 and TAP2 transporter gene polymorphisms in multiple sclerosis: no evidence for disease association with TAP. J. Neuroimmunol. 54: 35-40.

78. Wang F, Li X, Annis B, Faustman DL. (1995) TAP1 and TAP2 gene therapy selectively restores conformationally dependent HLA class I expression in type I diabetic cells. Hum. Gene Ther. 6: 1005-1017.

79. Touraine JL. (1981) The bare lymphocyte syndrome. Lancet. 1: $319-321$.

80. Gadola SD, Moins-Teisserenc HT, Trowsdale J, Gross WL, Cerundolo V. (2000) TAP deficiency syndrome. Clin. Exp. Immunol. 212: 173-178.

81. de la Salle H, Hanau D, Fricker D, et al. (1994) Homozygous human TAP transporter mutation in HLA class I deficiency. Science 265: 237-241.

82. de la Salle H, Zimmer J, Fricker D, et al. (1999) HLA class I deficiencies due to mutations in subunit 1 of the peptide transporter TAP1. J. Clin. Invest. 103: R9-R13.

83. de la Salle H, Houssaint E, Peyrat MA, et al. (1997) Human peptide transporter deficiency. J. Immunol. 158: 45554563.

84. Teisserenc H, Schmitt W, Blake N, et al. (1997) A case of primary immunodeficiency due to a defect of the major histocompatibility gene complex class I processing and presentation pathway. Immunol. Lett. 57: 183-187.

85. Furukawa H, Murata S, Yabe N, et al. (1999) Splice acceptor site mutation of the transporter associated with antigen processing 1 gene in human bare Iymphocyte syndrome. J. Clin. Invest. 103: 755-758.

86. Zimmer J, Donato L, Hanau D, Cazenave JP, Tongio MM, Moretta A, De la Salle H. (1998) Activity and phenotype of natural killer cells in peptide transporter (TAP) deficient patients (type I bare lymphocyte syndrome). J. Exp. Med. 187: 117-122.

87. Zinkernagel RM, Doherty PC. (1979) MHC-restricted cytotoxic $\mathrm{T}$ cells: studies on the biological role of polymorphic major transplantation antigens determining T-cell restriction-specificity, function and responsiveness. Adv. Immunol. 27: 51-177.

88. Ploegh HL. (1998) Viral strategies of immune evasion. Science 280: 248-253.

89. Früh $K$, Ahn K, Djaballah H, Sampe $P$, van Endert PM, Tampé R. (1995) A viral inhibitor of peptide transporter for antigen presentation. Nature 375: 415-418.

90. Hill A, Jugovic P, York I, Russ G, Bennink J, Yewdell J. (1995) Herpes simplex virus turns off TAP to evade host immunity. Nature 375: 41 1-415.

91. Lacaille VG, Androlewicz MJ. (1998) Herpes simplex virus inhibitor ICP47 destabilizes the transporter associated with antigen processing (TAP) heterodimer. J. Biol. Chem. 273: 17386-17390.

92. Tomazin R, van Schoot NE, Goldsmith K, Jugovic P, Sempe P, Fruh K, Johnson DC. (1998) Herpes simplex virus type 2 ICP47 inhibits human TAP but not mouse TAP. J. Virol. 72 2560-2563.

93. Ahn K, Gruhler A, Galocha B, Jones TR, Wiertz EJHJ, Ploegh HL. (1997) The ER-luminal domain of the HCMV Glycoprotein US6 inhibits peptide translocation by TAP. Immunity 6: 613-621.

94. Gilbert MJ, Riddell SR, Plachter B, Greenberg PD. (1996) Cytomegalovirus selectively blocks antigen processing and presentation of its immediate-early gene product. Nature 383: 720-722.

95. Hengel H, Koopmann JO, Flohr T, Muranyi W, Goulmy E, Hämmerling GJ. (1997) A viral ER-glycoprotein inactivates the MHC-encoded peptide transporter. Immunity 6: 623-632. 
96. Ambalga APN, Hinkley S, Srikummaran S. (2000) An early pseudorabies virus protein down-regulates porcine MHC class I expression by inhibition transporter associated with antigen processing. J. Immunol. 164: 93-99.

97. Rotem-Yehudar R, Groettrup M, Soza A, Kloetzel PM, Ehrlich R. (1996) LMPO-associated proteolytic activities and TAP-dependent peptide transport for Class I MHC molecules are suppressed in cell lines transformed by the highly oncogenic Adenovirus 12. J. Exp. Med. 183: 499-514.

98. Bennett EM, Bennink JR, Yewdell JW, Brodsky FM. (1999) Adenovirus E19 has two mechanisms for affecting class I MHC expression. J. Immunol. 162: 5049-5055.

99. Kring SC, Spindler KR. (1996) Lack of effect of mouse adenovirus type 1 infection on cell surface expression of major histocompatibility complex class I antigens. J. Virol. 70: 5495-5502.

100. Vambutas A, Bonagura VA, Steinberg BM. (2000) Altered expression of TAPI and MHC class I in laryngeal papillomatosis: correlation of TAP1 with disease. Clin. Diagn. Lab. Immunol. 7: 79-85.

101. Keating PJ, Cromme FV, Duggan-Keen M, et al. (1995) Frequency of downregulation of individual HLA-A and -B alleles in cervical carcinomas in relation to TAPl expression. $B r$. J. Cancer. 72:405-411.

102. Cromme FV, van Bommel PFJ, Walboomers JMM, et al. (1994) Differences in MHC and TAPl expression in cervical cancer lymph node metastases as compared with the primary tumors. Br. J. Cancer 69: 1176-1181.

103. Georgopoulos NT, Proffitt JL, Blair, GE. (2000) Transcriptional regulation of the major histocompatibility complex (MHC) class I heavy chain, TAP1 and LMP2 genes by the human papillomavirus (HPV) type 6b, 16 and 18 E7 oncoproteins. Oncogene 19: 4930-4935.

104. Seliger B, Harders C, Lohmann S, Momburg F, Urlinger S, Tampé R, Huber C. (1998) Down-regulation of the MHC class I antigen processing machinery after oncogenic transformation of murine fibroblasts. Eur. J. Immunol. 28: 122-133.
105. Kaklamanis L, Leek R, Koukourakis M, Gatter KC, Harris AL. (1995) Loss of transporter in antigen processing 1 transport protein and MHC class I molecules in metastatic versus primary breast cancer. Cancer Res. 55: 5191-5194.

106. Kaklamanis L, Townsend A, Doussis-Ananostopoulou IA, Mortensen N, Harris AL, Gatter KC. (1994) Loss of MHCencoded transporter associated with antigen processing (TAP) in colorectal cancer. Am. J. Pathol. 145: 505-509.

107. Kageshita T, Hirai S, Ono T, Hicklin DJ, Ferrone S. (1999) Down-regulation of HLA class I antigen-processing molecules in malignant melanoma: association with disease progression. Am. J. Pathol. 154: 745-754.

108. Vitale M, Rezzani R, Zauli G, Grigolato P, Cadeio M, Hicklin DJ, Ferrone S. (1998). HLA class I antigen and TAP downregulation in high grade primary breast carcinoma lesions. Cancer Res. 58: 737-742.

109. Alpan RS, Zhang M, Pardee AB (1996) Cell cycle-dependent expression of TAP1, TAP2 and HLA-B27 messenger RNAs in a human breast cancer cell line. Cancer Res. 56: 4358-4361.

110. Chen HL, Gabrilovich D, Tampe R, Girgis KR, Nadaf S, Carbone DP. (1996) A functionally defective allele of TAPl results in loss of MHC class I antigen presentation in a human lung cancer. Nat. Genet. 13: 210-213.

111. Kallfelz M, Jung D, Hilmes C, Knuth A, Jaeger E, Huber C, Seliger B. (1999) Induction of immunogenicity of a human renal-cell carcinoma cell line by TAP-gene transfer. Int. J. Cancer. 81: 125-129.

112. Seliger B, Höhne A, Jung D, et al. (1997) Expression and function of the peptide transporter in escape variants of human rental cell carcinomas. Exp. Haematol. 25: 608-614.

113. Restifo N, Esquivel F, Kawakami Y, Yewdell JW, Mulé JJ, Rosenberg SA. (1993) Identification of human cancers deficient in antigen processing. J. Exp. Med. 177: 265-272.

114. Wolpert EZ, Petersson M, Chambers BJ, et al. (1997) Generation of $\mathrm{CD}^{+} \mathrm{T}$ cells specific for transporter associated with antigen processing deficient cells. Proc. Natl. Acad. Sci. USA 94: 11496-11501. 